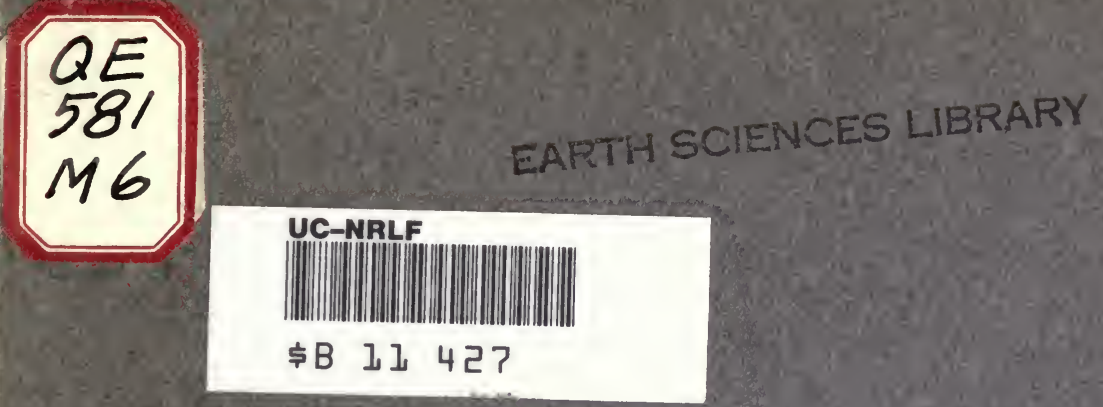




\section{EXCHANGE}

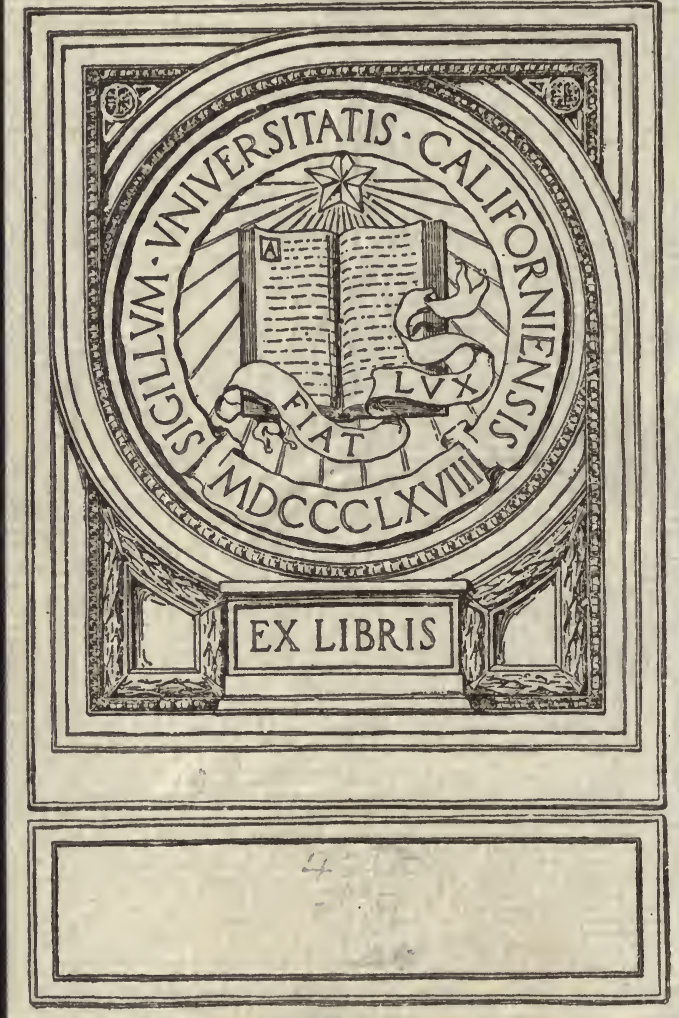




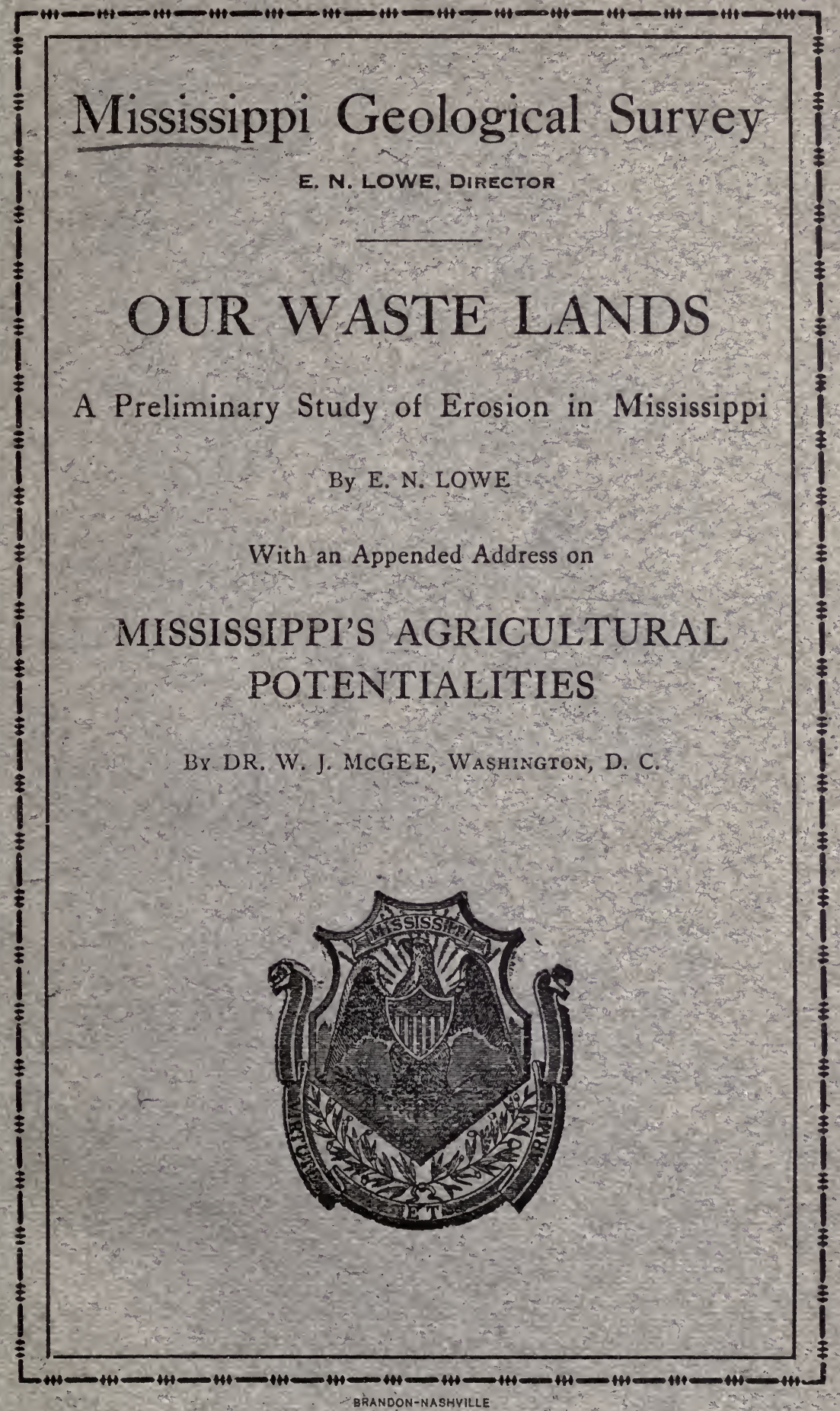


From the collection of the

- Prefinger $\int_{\text {vibrary }}^{\mathrm{z}}$

$t \quad p$

San Francisco, California 2006 


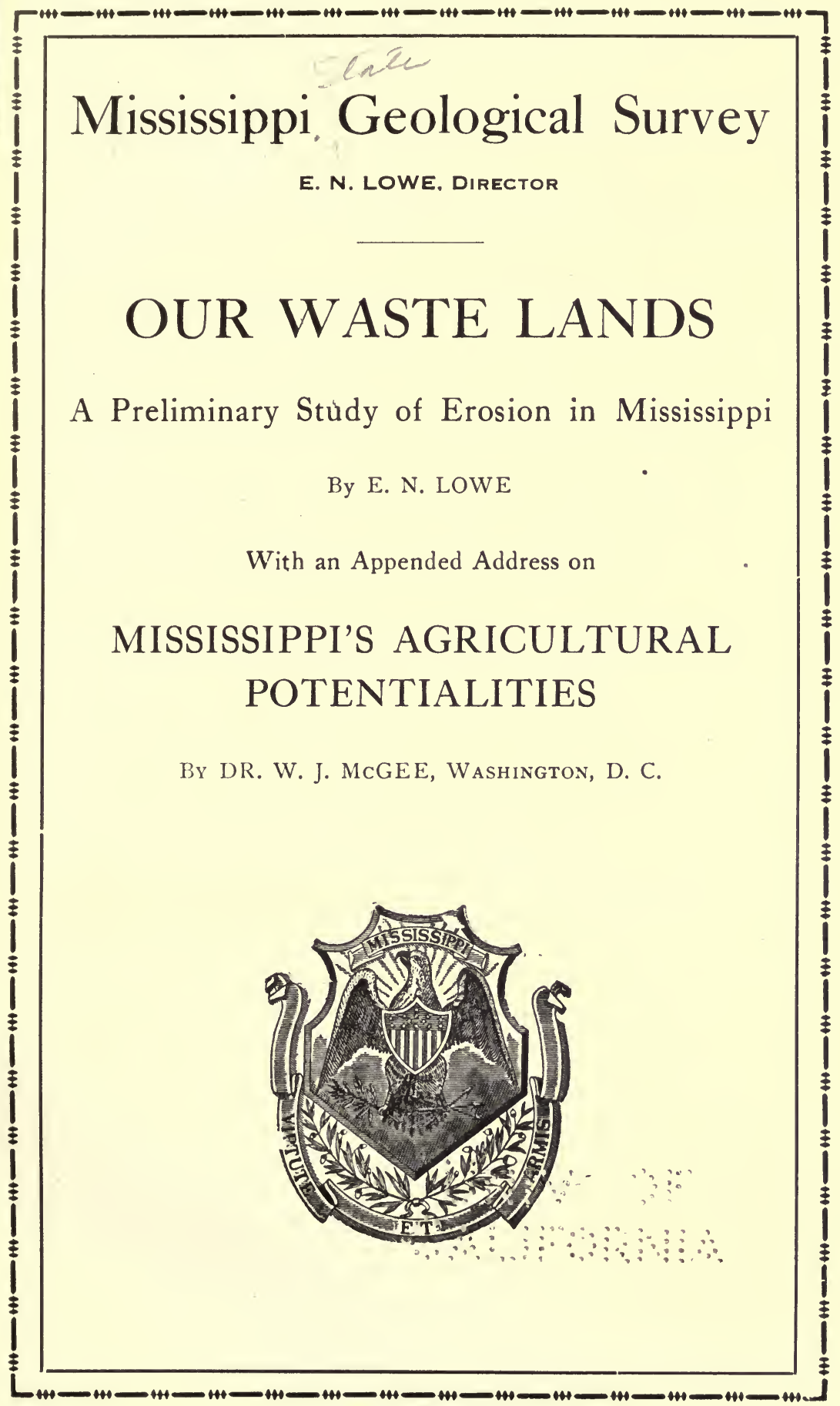




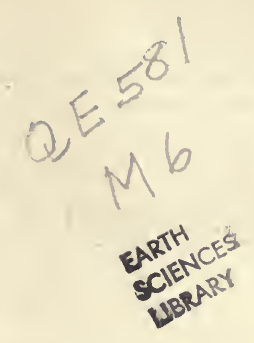

\section{PREFATORY NOTE}

This paper has been written to call attention to what the writer believes to be a serious problem in some parts of the State, which demands more than passing notice. It needs careful consideration, and needs it now, before the damage is beyond repair.

This short and hasty study of our eroded lands is preliminary to a more detailed study of the subject in all its aspects that will be taken up by the writer at as early date as the completion of work already in hand will permit. That study will be embodied in a Bulletin of moderate size and fully illustrated so as to show to the eye the results of erosion on the lands of the State and Nature's methods of repair when encouraged and supplemented by man's intelligent assistance.

The Paper of Dr. McGee, who has on a previous occasion given attention to soil erosion in Mississippi, has been introduced as well worthy of the careful perusal of every citizen of the State.

E. N. Lowe.

Jackson, July I2, I9Io.

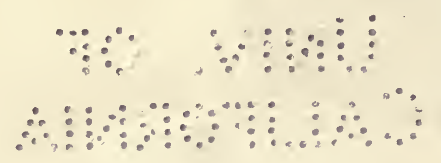




\section{OUR WASTE LANDS}

It may not be inappropriate at this time, since almost daily rains, frequently of torrential violence, have fallen in this State for a month past, to present a few facts about the washed lands that disfigure like ghastly scars all too much of the surface of our State. These trenched and scarred surfaces are so prominently developed in some sections of the State as to attract the unfavorable attention of every stranger passing through, and many years ago were graphically described by Dr. W. J. McGee of the U. S. Geological Survey, as the "Bad Lands" of Mississippi-a term we are in the habit of applying to regions of the Dakotas or Wyoming. Nevertheless, the term is descriptive of our conditions.

It is a fact well known that the surface soils of all lands, whether the slopes be gentle or steep, are slowly but surely, under the action of ordinary agencies of the weather, moving down toward and eventually into the sea. This is unavoidable and absnlutely beyond our control, though by various devices we may retard or check it for a while.

The process is normally very slow, permitting of the regeneration of the soil in any given locality as rapidly as it is removed. Under certain conditions, however, the removal of soil may be more rapid than its renewal, producing a condition of sterility which we ordinarily describe by saying-the soil is washed away. This is literally true, the soil of agricultural value is gone, and there remains a bare surface devoid of humus and other fertilizing elements necessary to farm crops.

This loss of the soil with consequent sterility is only the first step in a seriously dangerous process. The land, no longer productive, is thrown out and left to the tender mercy of the 
elements, as no longer useful. While being cultivated and frequently stirred the land will rarely be allowed to seriously wash. If the surface has slopes-and nearly all our lands have decided slopes-in cultivation it is either terraced or circled to prevent washing, and any wash that begins is filled with brush, or otherwise arrested. Not so when it is once thrown out, as so much of our land has been.

The heavy torrential rains that fall frequently in our climate soon furrow the slopes; if the slopes are steep the furrows quickly become gullies, and within a few years these may become tremendous washes, fifteen to twenty-five feet deep, and large enough to engulf a moderate-sized house. If the soil be sandy, or if underlaid by a sandy stratum a few feet beneath the surface, the destruction is all the more rapid. Beginning as they generally do on the lower slopes, these washes eat back farther and farther into the abandoned lands until the whole surface becomes cut to pieces.

Who of us have not seen what was once a field of swelling, graceful slopes now presenting an intricate maze of gullies and washes, until the original surface remains only as narrow crests between yawning chasms, or as clustered peaks and buttes which are but the finger marks of an even greater destruction. And all this because man has withdrawn his intelligent use of the soil. It may be asked, What are the conditions favoring this state of things? How do they operate? They are briefly stated below.

I. Slopes-especially steep slopes. Since all soils are moving toward the sea, which is their final resting place; it is evident that the steeper the slopes, other things being equal, the more rapid the removal will be. Hence, hilly lands, which have steep slopes, will wash most rapidly. The erosive power of running water varies with the square root of the velocity of flow, and since slope is the chief factor affecting velocity it will be readily understood why it is that washing begins on the steeper slopes of abandoned fields. 
2. Removal of forests and laying bare the soil to the direct action of the elements. The thick canopy of a forest, as well as the carpet of leaves and twigs beneath it, protect the forested surface from the erosive violence of heavy rains. Remove the forest and stir the soil and erosion is favored. This does not necessarily lead to evil results, however. The forests must be cleared and the lands must be cultivated for man's sustenance. and as long as he gives intelligent care to the soil washing need not result. It is only when he relinquishes it after clearing and cultivating it that it goes to destruction. Manifestly then care should be used in choosing lands to clear, leaving in woodland very hilly sandy lands, and especially if located near the headwaters of important streams, for forests are feeders of springs and springs are the only permanent feeders of our streams.

3. As intimated in the above paragraph, loose sandy soils and clayey loams underlaid by sands permitting undercutting and slumping favor washing of the land. This is patent to any intelligent observer. On the other hand, dense homogeneous structures, well compacted, yield less readily to erosion.

4. Heavy rainfall-particularly where it falls at times with torrential violence-rushing down the slopes with destructive force.

These are some of the most important factors influencing the rapid washing of the land. Let us apply them to conditions in Mississippi. Where is soil washing most active and where least so in the State?

Lying in the western part of the State is a broad, irregularly elliptical area, extending from Memphis to Vicksburg. This is the Mississippi-Yazoo Delta-a low-lying featureless plain built up of floodplain deposits, and the surface soils consisting of dark sandy loams near the streams and prevailingly sticky clays, "buckshot" or gumbo, in the interstream areas. All of this is very recent formation. 
Overlooking the Delta on the east like a great wall running from Memphis to Vicksburg in a sweeping crescent, then hugging the Mississippi River southward to the Louisiana line, are the Bluff of Loess Hills, rising I5O to 200 feet above the river, precipitous and extremely rugged. The capping of these hills to a depth of 20 to 40 feet is the Loess formation, a fine yellowish gray calcareous silt, with a thin blanket of a reddish brown clayey loam overlying it. This range of hills averages only a few miles in width.

All the reigon lying to the east, from the Tennessee line to the vicinity of Canton, and eastward to the Rotten Limestone prairies, is an ancient plateau of 500 to 600 feet altitude, now intricately dissected into hills and valleys and presenting on the whole a rough topography. This mature erosion antedates present conditions, the original slopes having been heavily timbered when the country was settled, and where the timber still remains washing of the land has not taken place.

Underlying most of this area is the Wilcox Formation of the early Tertiary, a formation consisting very largely of beds of sand with alternating clays. Above the Wilcox rests, over most of the area, a layer of orange red sand-the Lafayette, so called from Lafayette County-which varies in thickness from a few to twenty or more feet. The clayey loam which overlies the Loess spreads like a thin blanket over this area as well, where not removed by erosion.

In east Mississippi a broad area of gently rolling prairies marks the outcrop of a soft limestone of Cretaceous age. The soil is residual from the limestone on the whole, and is a dark sticky clay.

From Canton to Jackson and extending eastward across the State is a region of slight relief and of prairies somewhat similar to that of the Cretaceous area. A dense clay marl underlies the surface, the soil consisting of the residual materials of the 
marl, or of the Columbian clayey loam, already described as overlying the Wilcox and Loess regions.

All the southern half of the State, south of the Jackson prairie belt, consists of a maturely dissected plain gently sloping to the Gulf. The relief to within twenty or thirty miles of the Gulf coast is considerable, some of the hills being I 50 feet or more above the valleys, and the aspect presented in many parts is decidedly hilly and rough. The red sands of the Lafayette forms the surface soil over large areas east of the Illinois Central Railroad, the red clay loam overlying this in most of the region lying west of that road. The underlying formation over the whole area is the Grand Gulf, of alternating sandls and clays.

In the light of this brief study of the geological formations of the State we would be led to infer from their character and arrangement that, on the whole, erosion would be most active in the broad central belt of north Mississippi corresponding to the outcrop of the Wilcox Formation. It is most active here because the region is one of considerable elevation and of decided slopeshilly; the soil is sandy, or underlaid by sand, which becomres exposed on the slopes and permits undercutting; the rainfall is heavy-as elsewhere in the State; the timber has been very largely removed, and much of the surface lies out in old fieids. Erosion is hardly ever seen in the wooded parts, and then only by invasion from bordering fields, or after thinning of the forest has destroyed the natural balance in conditions under which the original slopes were developed. Confirmation of these statements can be found anywhere in that region.

The southern section of the State has such a large proportion of sand in the soil and surface formations that erosion progresses rapidly if unchecked, and over much of the surface washing of the lands is prominently developed.

The Loess or Bluff Hills present some of the most striking erosion features to be seen in the State. Great "gulfs" or chasnis with vertical walls dissect the uplands in places, though tine 
general surface shows less evidence of rapid erosion than the plateau region of north Mississippi. This may be accounted for in two ways: I. The Loess is highly calcareous, and for this reason possesses greater coherence than we would expect in a similar material without a lime cement. 2. The whole Bluff iegion is thickly carpeted with Bermuda grass, whose roots and underground stems protect the surface against rapid erosion.

The prairie regions of the State, as a whole, present little evidence of washing.

In the Delta we find least evidence of surface erosion becaise of the almost absence of slopes, which are necessary to develop erosive violence in the run off of the surface water. An entirely different principle is involved in the undercutting of streams, which is not considered here.

Resulting Damage- What are the damages resulting from surface erosion? They are numerous, a few of which will be noticed here.

I. Loss of fertility of soil, as before stated. The working of the land becomes unprofitable and its abandonment follows. There is here an evident lack of adaptability on the part of our farmers. They seem to have failed to realize that land unfit for certain uses may be very profitable for other uses.

2. Quick upon the heels of abandonment comes the cutting up of the surface into gullies and eventually into the unsightlv "bad lands," especially in a region of sandy soils and decided slopes.

3. In many cases the washing from the hills destroys the fertility of the smaller bottoms by spreading over them sand in layers, the thickness of which tends to increase from year to year. This is not an imaginary result, but is actually taking place in some of the northern counties of the state.

4. Loss of underground water results. This result is not so remote as might at first appear, and ere long these effects will be felt. Many springs that existed disappear, bold, strong springs 
become weak, wells become less certain-the level of ground water sinks-all because the feeder of the springs, the forest, has been removed, and only bare steep slopes remain which absorb little water, but shed it rapidly into the streams. These are flooded with devastating effects, and then in a short time go dry, because the springs that fed them are dry.

5. After every heavy rain myriads of gullies pour their torrents of mud and sand into the smaller streams, these pour their loads into the larger streams, and so thousands of tons of the wreckage of our fields eventually find their way into our great waterways - the navigable streams of the State-and they become navigable no longer-choked out of existence by the wasted wealth of our lands.

When we consider that before many decades our great waterways will be the pride of the State, and avenues by which our products may reach the seaboard and thence be transported to every quarter of the globe, how can we with patience see these God-given thoroughfares blotted out of existence when, with proper and timely attention, both they and the wealth of our lands may be conserved to us and our posterity.

6. Last, but perhaps not least, of the evils following the waste of our lands is the aspect of utter barrenness and desolation that is so prominent a feature of the "bad lands"- -an unsightliness repelling every intending settler in the region and filling with discouragement and discontent any already domiciled there, so that even they gather up their household goods and move to less forbidding parts. This is no picture of fancy. Considerable areas in north Mississippi have had that history. Sections once thickly populated we find now largely deserted, especially by white farmers, and the lands are rapidly going the way pointed out in the above paragraphs.

Remedies-Is there any remedy for this evil? Up till the present time a large proportion of our people have seemed to rgard this as unavoidable and consequent upon the wearing out 
of our hill soils. But the trouble can be remedied by proper effort. It could more easily have been avoided in the first place.

It is not the purpose of this paper to arraign those who have occupied the wasting lands in the past. The trouble grew out of natural conditions for which they were not responsible. Up till the Civil War conditions in Mississippi partook somewhat of those of a frontier state. Our methods of agriculture were crude and wasteful, but sufficient to extort from a virgin soil abundant sustenance for those occupying the land; the population was far too sparse to use all, or even the larger part of the land. With land so abundant it was but natural that if a field grew poor and unremunerative it was thrown out and more land cleared and put in cultivation, resulting in a double waste-a waste of land and a waste of forests. Frontier people are proverbially wasteful, and in those days Mississippi was a frontier state.

What are we to say of conditions following the war? For many years worse-far worse-than before. Our homes and lands had suffered the waste of four years of destructive war; our population had been decimated, the negroes were freed, and anxious to assert heir freedom moved away from the plantations. A large proportion became profligate and idle loafers, seeking the patronage and support of the Federal Bureaus.

Reconstruction days, worse if anything than the war itself, saw very little, if any, betterment of industrial conditions.

When finally things settled down and it became possible to begin the rebuilding process, Mississippi had a smaller white population than before the war, no money with which to operate and an unsatisfactory tenantry, idle and non-progressive. Necessarily much of the poorer land's had to be abandoned.

By far the greater part of the washed lands of the State have had this history. But conditions have now changed. Our population is doubled, the wealth of the State is vastly increased, and while our tenantry is not yet satisfactory, there are no longer the same forcible reasons, as once existed, why our waste lands 
should be neglected. Can they be remedied? Nature has furnished us several remedies which, with a little exercise of man's intelligence and energy, may become operative.

I. Old Field Pine-The name of this pine suggests the tendency so well known which the tree has to take possession of old worn-out fields. It usually grows very thickly over the whole surface; the seeds being very abundant and light, making them easily transported by the wind. When this pine once gets thickly set upon an old field the surface is protected from washing both by the canopy of the young forest and by the thick mat of needles, which also stop washes already begun. This may be observed in any of the old fields of the State occupied by this pine.

This is a valuable tree for future use for timber because of its quick growth and rapid reproduction. When it does not occur in old fields it should be planted, unless the area is to be used for pasture, when a different course may be pursued. For reforesting purposes it is one of the best, and much of our hilly lands should be reforested and kept in forest. In the long run the lands will prove most remunerative used in this way.

Considerable areas of the worn-out hill lands have from time to time reverted to the State for non-payment of taxes. Since the law gives the Governor authority to withdraw from sale lands so forfeited to the State, it might be a good present policy for the more hilly and sandy of these lands, particularly where favorably located to conserve the water of our streams, to be withdrawn from sale for an indefinite time, reset with a good growth of old field pines or other useful trees, and made the nucleus of a State forest reserve.

Should the increase of population in-Mississippi at some future time demand these reforested lands for agriculture, and it should be deemed a wise policy to do so, they can again be cleared and farmed with profit in small tracts on the intensive plan, though now no longer profitable as farm lands under present methods of culture. 
2. Lespedesa or Japanese Clover-This plant is not native to the State, but is thoroughly naturalized, and exhibits a marked tendency to take possession of old red hills and waste lands generally. It forms a thick mat, and if encouraged the least bit will carpet level land, hills and washes alike. It reaches down the gully slopes from above, takes possession of the bottom and creeps up to meet the carpet on the upper slopes, until the whole surface is captured. The wash is stopped and gradually fills.

This plant is a very valuable forage both when cut for hay and when pastured. Besides, being a legume its nitrogen-gathering tubercles enrich the soil. If not already growing there, it should be sown in all old fields turned out to pasture. The seeds can easily be obtained, and once set it reseeds itself.

The expression, "Fields turned out to pasture." should be corrected. Under no conditions should lands be "turned out." If fields prove no longer profitable used in farm crops it may be converted into pasture or a forest crop, giving it due attention and care. While a pasture or a forest may require less attention and labor than a farm crop, to be remunerative they must receive proper care. Under no circumstances must washing be allowed to begin, to prevent which the land must be kept well covered with its proper growth. Do not let your forage plant get thin in your pasture, nor your trees in your forest.

3. Bermuda Grass-As a forage and as a hay this grass is at least equal to the Lespedesa, and its power of capturing and stopping washes is even greater. It must be a very rapidly washing gully that Bermuda will not stop with its long knotty lace-like root-stocks. These grow very rapidly, reach out in every direction and root at every joint, and if for a few days the soil stops shifting the grass begins to lock it in its myriad fingers. Its power to stop washing is remarkable and best seen in the Bluff Hills between Vicksburg and Natchez.

The farmer of Mississippi has heretofore dreaded Bermuda grass, but it is one of his best friends; it feeds his stock and poul- 
try, holds the soil of his hills and enriches it with its decaying rootlets. The temporary inconvenience to the farmer in his field crops is more than repaid by its great usefulness. It should be more extensively propagated in the State, especially in those counties where washing is active. The seed may be sown, or better still, small pieces of the sod may be dropped along in furrows, and the area will soon be covered.

4. Black Locust-This is an invaluable tree to plant in thin soil and washed areas. It thrives in such places, sending out long fibrous roots, which, as the groves are usually thick, interlace so as to prevent or arrest washing of the land. It has been planted quite extensively in places for this purpose. But the tree is of moderately fast growth and soon attains a size suitable for fence posts; its wood is very durable and makes the best of posts or telephone poles. An acre of old washed land can support such a number as to make it a really valuable crop on lands that otherwise would be useless.

These are not all, but a sufficient number of these natural remedies to the evil of land washing, so that we have no difficulty in seeing where our wasting lands can be not only to a great extent reclaimed but made remunerative while undergoing reclamation. To these should be added well-directed, earnest effort of the people to reclaim these lands by all other available methods, even at cost of great labor. If there be doubt in the minds of any as to the possibility of the undertaking, they are invited to visit the Experiment Station at Holly Springs and see what intelligent work can do along this line. Professor Ames began work four years ago on certainly one of the most unpromising areas in Mississippi, which under his intelligent and skilled management, has been converted into a model farm, the unsightly washes that scarred its surface all removed.

The reclamation not only can be done, but must be done. We must fill up the vacant places with intelligent white farmersencourage immigration from the older states in every legitimate 
way. We have land to spare-they have people enough to spare to fill these lands. With proper inducements may we not expect to fill up our excess of lands with this thrifty, hardy class, as the newer states of the West have done? May the tide flowing across our northern border into Canada not be turned southward?

This is the most rational and feasible way, and perhaps only in this way can the problem be seriously attacked in a large way. As long as there is a disparity between land and population, as has existed heretofore, there will be waste. Certainly we are blamable if we fail to do all that can be done to reduce the waste of our land. It is not our heritage alone, but belongs equally to those who come after us. We fall far short of the promise of our civilization if we fail to develop that spirit of altruism that regards the man who lives after us as much our neighbor as the man who lives beside us. We cannot disregard the rights of either.

Lest some who may read the above discussion might draw the erroneous conclusion that our State is in worse condition than is actually the fact, and that a feature painfully prominent in certain regions is characteristic of the whole, it has seemed to the writer not remiss to present in conclusion something showing the reverse side of the dark picture drawn.

Could every reader of this paper but visit and see for himself all parts of our fair State, rich and beautiful, and pregnant with possibilities yet but half developed, no words would be necessary to convince the most pessimistic of her great future. Since such is not possible, however, no more fitting presentation of Mississippi's Agricultural potentialities can be produced than the appended address of Dr. W. J. McGee, of the United States Soil Bureau, who has done more to advance the knowledge of geological and soil problems in Mississippi than perhaps any man who has never resided within the State. 


\section{March 22, I9Io.}

My Dear Doctor Lowe:

A few days ago Honorable Joseph E. Ransdell of Louisiana apprised me of his intention to shortly deliver a speech before the Congress touching on the agricultural capabilities of Southern United States, with the object of counteracting the current tendency toward emigration, especially from northern United States to Canada; and he invited suggestions from me as to mode of approach and treatment. In talking over the matter, I mentioned to him my strong convictions concerning the agricultural possibilities of Mississippi (wihch are in large measure parallel to those of his own State), noting incidentally the fact that I had recently been favored with the opportunity of addressing the Legislature of Mississippi on the subject. He asked me to put the matter in writing; and I have just done so. While the points incorporated therein were brought out in your hearing in conjunction with other points not incorporated, it occurs to me that the writing may be of some service to you. Accordingly, I am giving myself the pleasure of enclosing a duplicate.

* * $\quad *$

$* \quad *$

Yours cordially,

W. J. McGeE.

Dr. E. N. Lowe, State Geologist, Jackson; Mississippi. 


\title{
AGRICULTURAL POTENTIALITIES OF MISSISSIPPI
}

\author{
By IV. J. McGee, LL.D.
}

(Synopsis of addresses delivered in special joint session of the State Senate and House February 5 and 8, I910).

Mississippi is essentially an agricultural State; with the possible exception of the neighboring commonwealth, Louisiana, it is the most completely agricultural State in the Union, and its manifest destiny is to fill the mouths of the rapidly growing population of less favored parts of the country. Of its thirty million acres, there is scarcely one not susceptible to cultivation and high productivity - though a few require drainage. No other states save possibly Louisiana and Iowa are so fully arable; and in climate it is superior even to these. Even beyond the unsurpassed fitness of its fair and fertile lands for the production of food is another value seldom reckoned until recently-its natural water supply. The average/rainfall of the United States is but 30 inches-hardly half that required for full productivity of the soil. The rainfall of Mississippi averages almost exactly 55 inches, or nearly enough for full productivity, while this supply is supplemented along its borders byjdrainage from half the rest of the country. 'Thus far there are those who think Mississippi's water supply excessive; but they have not learned the hard lesson of agriculture in the arid region. In the arid districts of this country, and of the world, this lesson has been conned long and mastered fully. Under intensive agriculture-as in its best developments in Arizona and New Mexico, California and Nevada - it has been found that five acres are enough for a family-that on five acres a family of five may live far more luxuriously and 
far less laboriously than the average family of the entire country lives on a quarter-section or even a section of fairly fertile land. Yet under this intensive farming it is not the land but the water that counts; for each of the five acres of homestead must receive about five acre-feet of water yearly. Now this, water weighs more than 6,000 tons; the first foot of soil which sustains the plants weighs but 2,000 tons and lasts for uncounted generations; but in order to sustain its inhabitant each acre must inse three times the weight of its soil in water, and this during each year. The lesson of the arid region, by which Mississippi will one day profit, is that of the paramount value of water among the resources of the earth; and in this paramount resource Mississippi with its neighbor on the southwest are richer than any others among our commonwealths, save in a few others less favorably conditioned in other respects. Mississippi has the land; she also has the water; she has skies fair as those of Italy; a climate finer than that of the Mediterranean, so that within her borders the stream of life flows easily and steadily.

Those there are indeed who repine because this fair State lacks those mineral resources commonly supposed to form the foundation of industrial activity and material prosperity; but they err. It were worth while to make a comparison or two, not invidiously since each commonwealth of our Union is not only sovereign but splendid in its way-yet none the less instructively. Consider then that State best supplied with coal and iron, which more than any other made this a manufacturing nation great among the nations of the globe. Her wealth is vast, her population is large, yet it were well to remember that fạr the greater part of her wealth is concentrated in a few monopolies and controlled by a few monopolists, and that by far the greater part of her people are industrial dependents. She has wandered far from the standards of the Founders of this Union of States, of which the ideal was a free landed citizenry, each citizen the peer of all the rest-that ideal toward which Mississippi more 
closely approaches today than almost any other commonwealth of the Union. One born on the banks of the Mississippi in Iowa and who has worked much on the banks of the lower river in the commonwealth bearing its name may be pardoned for pointing out a similarity and a difference. In these two commonwealths of the interior every white male child born on any day or in any year has an equal chance with all others to become Governor of his State or President of the Union, while in the commonwealth of coal and iron not one male white child in a hundred born on a given day or in a given year has the slightest chance of even seeing the inside of gubernatorial or presidential offices. Such is an effect of industrial dependence, with the social differentiation rooting within it. Nor is this all; the effect goes on to personal character, to conscience, to the springs of patriotism. Here in the State of farms dwells uprightness; there amid the smoke of manufacture the seeds of corruption spring easily as amid the tyrannies under which Rome fell of old. Now a single further straw: Your State of farms and the State of factories about the same time began the erection of new State Houses; this stately edifice was constructed at a total cost of a million honest dollars; in the other, no more fit and hardly more commodious or elaborate, the graft in the furnishing alone amounterl to fully five times the cost of your capitol. Truly the farmer State has no reason for repining!

Another and more agreeable comparison may be made: Two generations ago a tale of gold came out of the West; it reached this State, among others, and inspired the strongest and most ambitious among the sons of South and North alike. As in the search for the Golden Fleece long ago, so the later argonauts went forth on a pilgrimage-one of the hardest ever made by men. The picked offspring of strongest sires and dames, they faced harsh nature and treacherous foe, and with unsurpassed effort wrested richer treasure from the rocks than was known before. So California arose as a golden State, conspicuous among our 
commonwealths for mineral production. It was and remains a great gold producing State, so rich in production that comparatively few Americans think of it except as a gold producer, yet the practical fact is that during last year, during the year before, during each year for a decade her agricultural production has aggregated more for the single year than her entire production of gold during all her history! Here Mississippi may well find a lesson. And what are California's productions? Not cotton or corn or cane, the staples of the South, not so much the wheat or potatoes or barley of the North, or indeed any other staples, as those ill-considered trifles on which the Mississippi planter looks askance-the berry, the small fruit, the minor vegetable. which is here relegated to the fence row or the neglected garden corner. And why do Californians not grow the staples for which their soils and climate are no less adapted than those of the interior? Merely because they cannot afford it. Corn cannot be grown with profit on land worth a hundred dollars an acre. nor cotton on three-hundred-dollar land, nor cane on four-hundred-dollar land; while the berry and fruit lands of California are worth five hundred, a thousand, even several thousand dollars per acre. Now when will Mississippi take heed of California's example? When she does, the boll weevil, now seen as a calamity, will be viewed as a blessing. The orange and the lime may not indeed flourish here as there, save in the southernmost part of the State, yet the fig, the apricot, the prune, and the berry may be made to fit this soil and climate no less than those of the Pacific State-indeed if one would look at the map of the wordi and trace the lines of temperature and rainfall with risk of ir sst and danger of excessive sun one would be compelled to co.1clude that this commonwealth is adapted to practically every production of the temperate zones of both hemispheres. Truly the potentialities of this commonwealth have been but half reclized!

Let it not be supposed that the State is stagnant industrially 
or otherwise; for in truth it is in rapid progress along its lines. Just twenty years ago I traversed the entire length of the State horseback, meandering back and forth from the river bluffs and the deltas well into the hill country covering a zone say fifty miles wide from Woodville to Holly Springs; then the agricultural value of the State probably ran about ten dollars per acre, or three hundred million dollars. To-day it cannot be less than twenty-five dollars an acre, or seven hundred and fifty million dollars; and if ordinary foresight, guided by the light of scientific methods now coming in and of experience in other States is worth anything, in another twenty years the value will nearly quadruple, and approach a hundred dollars an acre or three billion dollars for agricultual Mississippi.

Nor will this be the end, or indeed mark anything more than the threshold of Mississippi's prosperity. In the past twenty years the population of the State has increased steadily to the present two million; but it seems probable that the greater share of this increase is in urban rather than rural inhabitants. Now. to what ultimate population should Mississippi look forward? Remembering that the capacity of a country for production and population is fixed first by water supply and second by land area, a rough estimate may be made. On the basis of the intensive farming of irrigated Arizona, Mississippi's thirty million acres would sustain an agricultural population of thirty millioni. e., a family on each five-acre lot throughout the length and breadth of the commonwealth-or a total equal to one-third the present population of the United States. This would mean an average density of 640 inhabitants per square mile, almost exactly that of Belgium on far less fertile land than this. Would the area suffice for such a vast people? Undoubtedly, if the experience of New Mexico and Arizona and California affords a criterion. Would the water supply suffice? Undoubtedly, provided the population were primarily agricultural $-i$. $e$., provided the land were made productive to something approaching its limit. 
Few realize the quantity of water required to sustain a population-much less that water is the prime requisite of life, vegetable and animal no less than human. Some six-sevenths of our bodies and of the food we consume consist of water; there is no assimilation, none of that essential process of growth called metabolism, no germination, no reproduction, no form of life whatever in the absence of water or otherwise than as the expression of inherent properties of water. The average adult subsists on a ration amounting in a year to the equivalent of 200 pounds of bread and a like amount of meat; but in addition he consumes some 2,000 pounds, or a ton, of water. Now to produce the 200 pounds of bread requires for the growth of the grain from which it is made the use in the vital processes of the plants of not less than 400 tons of water; and to produce the 200 pounds of meat there are required for the drink and the making of the food of the animals yielding it no less than 4,000 tons of waterso that the water ration of the average adult inhabitant exceeds 4.400 tons annually. Now the natural water supply of Mississippi in the form of rain is nearly 6,000 tons per acre; so that if the acres are made productive she can sustain an inhabitant to the acre, and leave a sufficient margin for a moderate urban population-indeed for all the cities required as marts and commercial centers. Yet any such development will involve improvement of the soil, growth in rural population, enhancement in the value of the farm-indeed continuous progress in conformity with the ideals of the founders of the Union in the form of a landed citizenry.

Perhaps the standard of thirty million population in this commonwealth may be too remote for practical consideration to-day; yet the conditions involved are not too unreal for careful weighing-they merely emphasize the fundamental fact that Mississippi must be a producing State and that her chief productions must come from the soil. Her capital lies in her soil and her natural waters. Long before her population reaches its limit she 
must become a feeder for less favored commonwealths; and toward this end she may well lay plans to-day. Fortunate as she is in her natural endowment, how many of her fellow citizens beyond her borders know of Mississippi as a food-producing State? The markets of the country display Oregon apples, California raisins, Arizona pomegranates, Colorado cantaloupes, Louisiana rice, Florida Oranges, New Mexico grapes, Washington potatoes, Michigan celery, New Jersey asparagus, and legion other delectable productions crystallized in the memories of connoisseurs by the names of States or counties or valleys; but how seldom we find the name of Mississippi, a State more favored than all the rest. Today the gourmet in Chicago or Cincinnati either scans the menu in vain for that modern food of the gods, okra, or is put off with a concoction two parts tomato-the oikra so adapted to Mississippi that it grows easier than not, and if planted on an acre would yield four times the product in potatoes with five times the nutriment, pound for pound, and many times the market value. California may rival Mississipp in the prune and outclass her in the orange; but in okra Mississippi will excel the rest of the world. And this is but a single product out of many that might be noted! Consider just one more: The most nutritious known food is the rich meat of nuts; and the fincst nut known is the paper-shell pecan which takes to Mississippi soil so avidly that it can be eradicated only by much effort. Surely the planter setting out on his career could not do botter than to put out a score of these trees in his least promising quarter-acre; for by the time his son becomes a big school boy he can harvest enough not merely to relieve the monotony of a rural diet, but go far toward supporting the entire family diuring the year in which the staple crops fail either in yield or in price.

So let Mississippians weigh as they will the prospects for the future; in the end the view must swing rowid in the direction of steadily increasing prosperity, of growing population, of arvanc- 
ing values, of rising reputation as a source of food, not only for her own but for other peoples, domestic and foreign. Nature adapted this as the garden State; and her sons and her daughters may well follow exuberant nature's lead. Her capital lies in her soil and water; and her greatest need today is for systematic development of the one in such manner as to best utilize the other, to the end that crops from the soil made abundant and luscious by the ample water supply may sustain an ever-increasing, intelligent and contented people. As her permanent capital, the soil of the commonwealth is worthy of first and closest attention; no pains or reasonable cost should be spared in the scientific study and classification of the soil; every acre should be considered with a view to its best adaptations, since it is the last few pounds or bushels of product that yield clear profit. So, too, the disposition of the product should be considered; the pig driven to market carries the equivalent of tons of plant product, the egg bears the equivalent of pounds of green food and grain-and both leave useful by-products of nature's laboratory to enrich rather than impoverish the farm. The time has gone by when farming was but a chapter of accidents, or at the best a series of random experiments; the time is at hand when the acutest intelligence of the American people and the most refined applications of modern science must be found on the farm-and it is no less true today than at the birth of English letters that "Tlie farmer feedeth all."

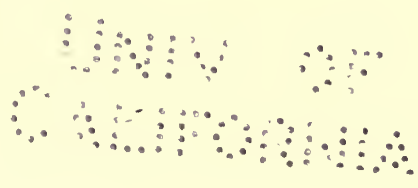




EARTH SCIENCES LIBRARY

This book is due on the last date stamped below, or

on the date to which renewed.

Renewed books are subject to immediate recall.

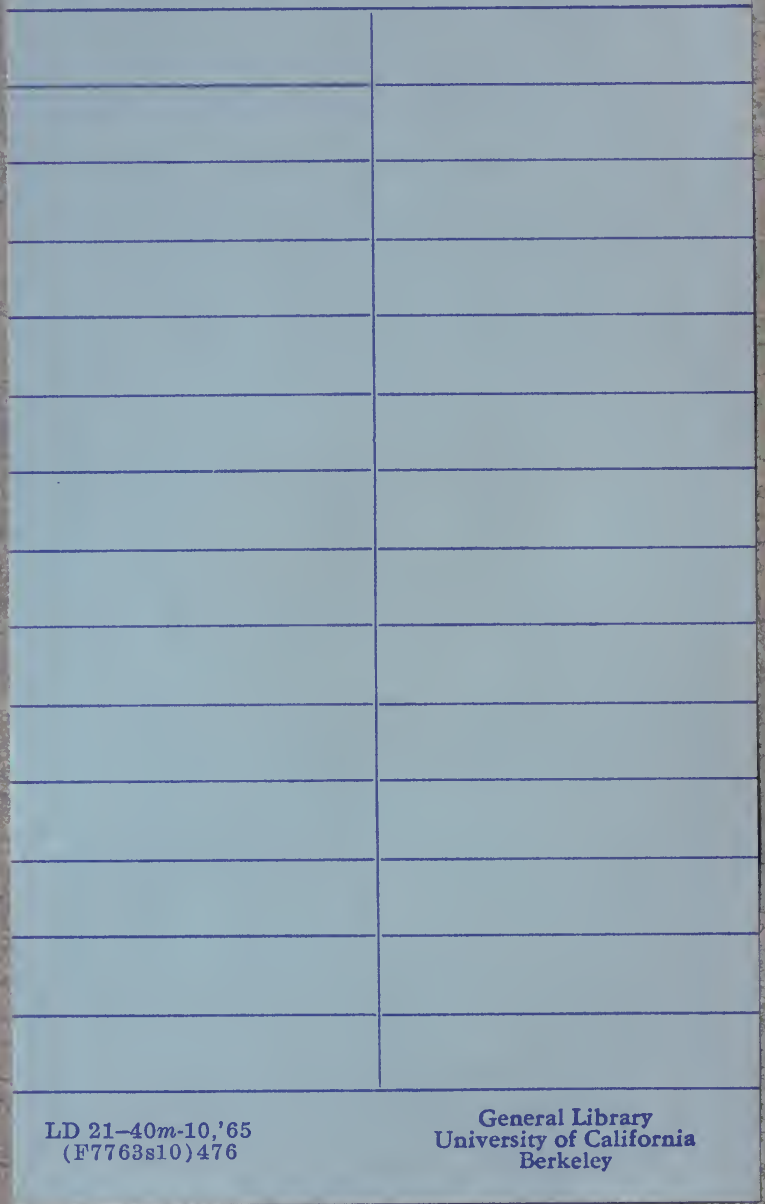


Gaylord Bros. Makers

Syracuse, N. Y

PAT. JAN. 21, 1908

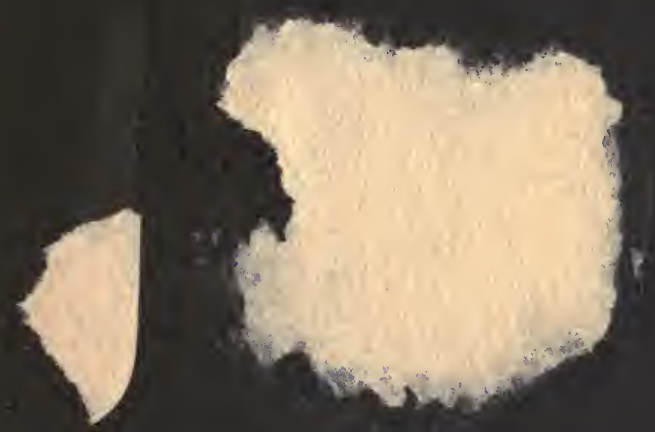


